\title{
Optics education at the Center for Research and Education in Optics and Lasers (CREOL)
}

\section{Moharam, M. Soileau}

M. G. Moharam, M. J. Soileau, "Optics education at the Center for Research and Education in Optics and Lasers (CREOL)," Proc. SPIE 2525, 1995 International Conference on Education in Optics, (13 October 1995); doi: $10.1117 / 12.224074$

SPIE Event: SPIE's 1995 International Symposium on Optical Science, Engineering, and Instrumentation, 1995, San Diego, CA, United States 


\title{
Optics Education at the Center for Research and Education in Optics and Lasers (CREOL)
}

\author{
M. G. Moharam and M. J. Soileau \\ Center for Research and Education in Optics and Lasers (CREOL), University of Central Florida, \\ Orlando, Florida 32816-2700 \\ Voice: (407) 658-6833, Fax: (407) 658-6880, E-ail: moharam@creol.ucf.edu
}

\begin{abstract}
We present an overview of the current status of optics education at the Center for Research and Education in Optics and Lasers (CREOL) and the University of Central Florida (UCF). The academic organizational structure of this interdisciplinary program is outlined.. Three graduate MS and Ph.D. degree programs in optical science and engineering, electro-optics, and optical physics are offered and coordinated by CREOL. The infrastructure, faculty, and research facilities dedicated to the optics education program are presented. Details of the admission, articulation, degree requirements, optics course offerings, thesis/dissertation research activities, and typical plans of study are included.
\end{abstract}

Keywords: Optics education, graduate programs, curriculum

\section{INTRODUCTION}

The University of Central Florida (UCF) is one of nine comprehensive universities in the Florida State University System. UCF, founded 25 years ago, has current enrollment of 25,000 students and offers 78 baccalaureate, 45 master's, and 14 doctoral degree programs in five colleges. UCF grants, on average, over 750 master's degrees and 40 doctoral degrees per year. A stated goal of UCF is to "achieve international prominence in key programs of graduate study and research by the year 2000". Optics education and research have been identified as one of these select targeted programs. This is in recognition of the rapid expansion of high technology optics, lasers, and opto-electronic industries. In particular, the cluster of laser and electro-optical companies in Central Florida is one of the three largest in the world involving over forty companies and employing over 2,000 scientists and engineers.

The Center for Research and Education in Optics and Lasers (CREOL) was established at UCF in 1987 as the Florida State University System's Center of Excellence for research and education in electro-optics and laser. The primary goal of CREOL is to help the electro-optics, laser, and opto-electronics industries by providing an educated work force, providing opportunities for advanced education for its scientists and engineers, developing collaborative research and development projects, and conducting fundamental research for future industries and products. From its inception, CREOL have been structured as an interdisciplinary academic center to bring the elements of many diverse disciplines involving optics into a cohesive optics research and educational program.

CREOL and the University of Central Florida offer a comprehensive graduate education in the interdisciplinary area of optics. Three distinct MS and Ph.D. program options are offered: 1) Optical Science and Engineering, 2) Electrical Engineering Electro-Optics option, and 3) Optical Physics. In this review, the objective of each of the three optics degree programs is outlined. The admission, articulation, and degree requirements are described. Optics course offerings, current thesis/dissertation research activities, and typical plans of study are presented. The infrastructure, faculty, research laboratory facilities and resources supporting the education programs are presented

\section{CREOL- AN OVERVIEW}

The Center for Research and Education in Optics and Lasers (CREOL) is an interdisciplinary academic center at the University of Central Florida. It was established in 1987 with the purpose of bringing diverse disciplines together in a cohesive research and educational program to provide students with a comprehensive education in optics and lasers. CREOL is supported by an annual base university allocation of approximately $\$ 3,000,000$ for 29 fully funded faculty lines and center operation. External contracts and grants from federal and state agencies and industrial corporations provide an additional $\$ 4,000,000-5,000,000$ per 
year. CREOL occupies over 50,000 sq. ft. housing 60 laboratories.fully equipped with state-of-the-art research equipment. These facilities will be shortly (Fall 1995) moved into a new 82,000 sq. ft building designated for optics research and education.

CREOL has grown to an internationally recognized center for optics education and research with 23 academic faculty members and five associate faculty from other UCF departments. In addition, 20-25 Ph.D. level research scientists and engineers are involved in research projects in optics. All CREOL faculty also hold tenured/tenure earning regular faculty positions in various academic departments (Electrical Engineering, Physics, Chemistry, and Mechanical Engineering, etc.). CREOL is in growth mode and is currently recruiting faculty to fill six remaining tenure-track positions.

The research activities at CREOL are integrated with the academic program to insure involvement of both students and faculty. The academic program involves students from several science and engineering departments. There are presently 75 graduate students and 10 undergraduate students at CREOL pursuing various degrees. MS and Ph.D. in degrees optical sciences and engineering, optical physics, electrical engineering, Mechanical Engineering, and other related programs are offered at UCF. The program includes over 23 specialized courses in optics and lasers as well as basic electrical engineering, physics, mechanical engineering, and chemistry courses. CREOL research activities reflect the interdisciplinary nature of the program. Current research areas include: acousto-optic signal processing and devices, infrared systems, laser/material interaction, nonlinear optics, laser development, free electron lasers, solid state lasers, laser host material growth and characterization, optical glass characterization, diffractive optics, opto-electronics, integrated guided-wave optics, optical switching, optical data storage, high speed optical communications, optical design and image analysis, X-ray optics and devices, remote sensing, and laser radar. This wide range of activities allows students to participate in areas of research that match their individual interest and career goals. CREOL has active collaborative interaction with national and Florida-based industry through an industrial affiliates program and individual faculty interaction. This relationship has played a very positive roll in influencing the direction of the educational and research activities. It provides research and employment opportunities for our students. CREOL faculty members have extensive collaborative efforts with international universities and corporate research organizations.

\section{OPTICS DEGREE PROGRAMS}

CREOL and the University of Central Florida offers comprehensive graduate education in the interdisciplinary area of electrooptics and lasers. Optics is inherently an interdisciplinary field that encompasses elements of electrical engineering, applied physics, material sciences and engineering, chemistry, computer sciences, and mathematics. Recognizing the diverse nature of optic education, three distinct MS and Ph.D. program options are offered: 1) Optical Science and Engineering, 2) Electrical Engineering - Electro-Optics option, and 3) Optical Physics. The first two programs are offered through the Department of Electrical and Computer Engineering and the third program is offered through the Department of Physics. The optics courses are offered in the various academic departments including: Electrical and Computer Engineering, Physics, Mechanical Engineering, and Chemistry. CREOL provides all the curricula development, faculty, laboratory facilities, and other resources to support these programs, and the degrees are awarded in the appropriate department/college.

The optical physics degree program is designed for students of a background in physics who are interested in quantum optics/electronics and fundamental light matter interaction. The electro-optics program is for students with a background in electrical engineering who are interested in the engineering application of optical devices and systems. The optical science and engineering degree program is designed for students with various backgrounds who are interested in an interdisciplinary applied optics oriented educational program. The main differences between the three programs are in the selection of the appropriate dissertation/thesis topic and the relative content (mix) of the course work among the electrical engineering, physics, and optics components. The availability of these three programs provides the student with an opportunity to select the educational program that best meets their individual background, interests, and career objectives.

\subsection{Program Description:}

\subsubsection{Admission}

For admission to the MS program, the applicant must have completed a Bachelor's degree with a major in electrical engineering, physics, optics or other appropriate discipline with a minimum grade point average of 3.2 out of 4.0 in the last 60 hours of undergraduate studies. For admission to the Ph.D. Program, the applicant must have completed a master's degree with a major in electrical engineering, physics, optics, mathematics or other appropriate discipline with a minimum grade point average of 3.5 
out of 4.0 in the graduate program. A cumulative Graduate Record Examination (GRE) score of 1100 is required. International students whose native language is not English will be required to have a minimum score of 550 on the TOEFL.

\subsubsection{Articulation:}

Undergraduate articulation courses may be required of students with BS and/or MS degrees in fields other than electrical engineering, physics, and optics. The articulation courses are determined, on a case by case basis, by the graduate coordinator in consultation with the student's research advisor.

\subsubsection{Master's Program}

The thesis option program consists of 24 credit hours of course work in addition to the thesis hours. The course hours are divided into optical science and engineering, electrical engineering, physics, and mathematics electives. The student must conduct a program of scientific investigation involving creative elements and submit a written thesis detailing these investigations. An oral defense examination for the thesis is required. The non-thesis option program consists of 36 credit hours divided among optical science and engineering, electrical engineering, physics, and mathematics electives. A final comprehensive written examination is required. Students may transfer up to six semester credit hours of approved graduate courses taken at other institutions.

\subsubsection{Doctoral Program:}

The program consists of 60 semester hours of course work in addition to dissertation hours. The course hours are divided among optical science and engineering, electrical engineering, sciences or mathematics electives, independent studies, and research. Students with a MS degree may transfer up to thirty six of approved graduate semester credit hours towards the $\mathrm{Ph} . \mathrm{D}$. degree requirement. Admission to the Doctoral program is contingent upon passing the Qualifying Examination. It consists of both written and oral portions and covers all material included in the core courses. A Candidacy Examination covering the course work and the general knowledge in the student's specialty area is required. The student must submit a written Dissertation Proposal describing the dissertation topic chosen by the candidate. An oral examination covering the details of the research project is conducted. Upon completion of the original scientific research program, a written Dissertation describing the student's research must be submitted. An oral defense for the dissertation is required.

\subsection{Plan of Study}

The plan of study is tailored to meet the specific background and career objective of the individual student. A typical plan of study for each of the MS and the Ph.D. degrees in optical and science and engineering are given below. The plan of study for the electrical engineering (electro-optics) and for the optical physics degree programs are similar but with a larger component of electrical engineering or physics courses, respectively .

Table I. Plan of Study for the MS Program

\begin{tabular}{|l|l|c|l|c|}
\hline & \multicolumn{2}{|c|}{ Thesis Options } & \multicolumn{2}{c|}{ Non-Thesis Options } \\
\hline & \multicolumn{1}{|c|}{ Courses } & Credit Hour & \multicolumn{1}{c|}{ Courses } & Credit Hour \\
\hline Semester 1 (Fall) & Wave Optics & 3 & Wave Optics & 3 \\
& Geometric Optics & 3 & Geometric Optics & 3 \\
& Radiometry\&Detection & 3 & Radiometry\&Detection & 3 \\
\hline Semester 2 (Spring) & Fourier Optics & 3 & Fourier Optics & 3 \\
& Electro-Optics & 3 & Laser Principles & 3 \\
& Elective & 3 & Elective & 3 \\
\hline Semester 3 (Fall) & Laser Engineering & 3 & Electro-Optics Lab & 3 \\
\cline { 2 - 5 } & Elective & 3 & Electives & 6 \\
\hline Semester 4 (Spring) & Thesis & 6 & Laser Engineering & 3 \\
& & & Advanced Topics & 3 \\
\hline Total Credit Hours & & 30 & & Elective \\
\hline
\end{tabular}


Table II. Plan of Study for the Ph.D. Program

\begin{tabular}{|l|l|c|l|c|}
\hline & \multicolumn{2}{|c|}{$\begin{array}{c}\text { Students with MS in } \\
\text { Optics or Electro-optics }\end{array}$} & \multicolumn{2}{c|}{$\begin{array}{c}\text { Students with MS in } \\
\text { other Related Fields }\end{array}$} \\
\hline & \multicolumn{1}{|c|}{ Courses } & Credit Hour & \multicolumn{1}{c|}{ Courses } & Credit Hour \\
\hline Transfer from MS & & 30 & & 30 \\
\hline Semester 1 (Fall) & $\begin{array}{l}\text { Optical System Design } \\
\text { Special Topics }\end{array}$ & 3 & Wave Optics & 3 \\
& Electives (E/M) & 3 & Geometric Optics & 3 \\
& Radiometry\&Detection & 3 \\
\hline Semester 2 (Spring) & Electro-Optics & 3 & Electro-Optics & 3 \\
& Laser Engineering & 3 & Fourier Optics & 3 \\
& Qualifying Exam & & Laser Principles & 3 \\
\hline Semester 3 (Summer) & Elective (Math) & 3 & Elective (E/M) & 3 \\
\hline Semester 4 (Fall) & Nonlinear Optics & 3 & Electro-Optics Lab & 3 \\
& Advanced Topics & 3 & Qualify Exam & 3 \\
\hline Semester 5 (Spring) & Electives & 6 & Laser Engineering & Advanced Topics \\
& & & & 3 \\
\hline Total Credit Hours & & 60 & & 60 \\
\hline
\end{tabular}

\subsection{MS and Ph.D. Graduation Record}

CREOL Faculty has supervised to completion over $115 \mathrm{MS}$ students and $37 \mathrm{Ph} . \mathrm{D}$. students in the field of optical science and engineering, electrical engineering (electro-optics), and optical physics since 1989. The Ph.D. degree in optical science and engineering has been recently established and the first graduate in the program is expected in the 1996. A total of ten Ph.D. students have graduate in the 1994-1995 academic year. Typically, it takes a student 20 month to complete the MS program and 3 years after the MS degree and 5 years after the BS degree to complete the Ph.D. program. The number of MS and Ph.D. graduates by year are listed in Table III.

Table III. MS and Ph.D. Graduation at CREOL

\begin{tabular}{|l|c|c|c|c|c|c|c|}
\hline Year & 1989 & 1990 & 1991 & 1992 & 1993 & 1994 & 1995 \\
\hline MS Graduates & 9 & 14 & 15 & 18 & 19 & 20 & 20 \\
\hline Ph.D. Graduates & 2 & 2 & 3 & 7 & 5 & 8 & 10 \\
\hline
\end{tabular}

\section{OPTICS COURSES}

Course work includes over twenty three specialized courses in optics as well as basic electrical engineering and physics courses. These courses, taught by CREOL faculty, are offered in the Electrical and Computer Engineering, Physics, and the Mechanical Engineering Departments. Typically ten or more optics courses are offered in each semester. Advanced Topics and Special Topics courses are also offered periodically. New courses are added to the program as needed to maintain the education program at the leading edge of technology. A list of the optics courses, including a short description, is given below.

\section{EEL-4440 Optical Engineering}

Lens system, aberrations, sources, radiometry, detectors, physical optics, interferometric devices, applications to engineering design problems.

\section{EEL-5441 Introduction to Wave Optics}

Electromagnetic foundation of light waves as applied to reflection, refraction, diffraction, interference, polarization, coherence, and guided waves. 
EEL-5450 Thin Film Optics

Principles of thin film optics and its applications in optical electro-optical, and laser systems.

\section{EEL-5453 Geometrical Optics}

Foundation of geometric optics, geometrical theory of image formation, optical system layout, introduction to optical system design.

\section{EEL-5451 Electro-Optics Laboratory}

Study of laboratory techniques for optical measurements and performance of measurements on electro-optic devices to determine operational characteristics.

\section{EEL-5563 Fiber Optics Communication}

Use of fiber optics as a communication channel, principles of fiber optics, mode theory, transmitters, modulators, sensors, detectors, and demodulators.

\section{EEL-6443 Electro-Optics}

Propagation of Gaussian beams, principles, design and use of birefringent and periodic electro-optic devices, the Electro-optic effect and electro-optic modulators, the photo-elastic effect and acousto-optic devices, nonlinear and phase-conjugate optics.

\section{EEL-6446 Optical Systems Design}

Design principles of lens and mirror optical systems; evaluation of designs using computer techniques.

\section{EEL-6457 Advanced Topics in Electro-Optics}

Current research topics in electro-optics, such as optical computing, binary optics, advanced system design issues, novel laser systems.

\section{EEL-6560 Laser Engineering}

Principles of laser amplification and oscillations; design of lasers; general characteristics of excitation systems.

\section{EEL-6561 Fourier Optics}

Application of Fourier transform theory to optical systems design, development of optical correlation techniques, holographic techniques and applications.

\section{EEL-6564 Optical Communication Theory}

optical communications schemes, statistical modeling, coherent and noncoherent detection time synchronization, channel characterization

\section{EEL-6565 Radiometry and Detection}

Radiometry, Plank radiator, spectrometer, photon-counting statistics, detector noise, detector mechanism.

PHY-4244 Optics

Wave Optics, absorption, stimulated emission, lasers, transforms, coherence, holography.

PHY-4244L Optical Physics Laboratory

A laboratory course on geometric optics, interference, diffraction, materials and modern optics.

PHY-5431 Optical Properties of Materials

Normal modes (dipole and Raman active); microscopic theory of absorption, dispersion, and refraction; wave propagation, crystal optics; scattering mechanisms, optical activity.

\section{PHY-5446 Laser Principles}

Classical introduction to the basic principles of laser gain media, properties of laser resonators and modes, description of specific laser systems.

\section{PHY-6434 Nonlinear Optics}

Maxwell's equations in nonlinear media, frequency conversion techniques (SHG, SFG, OPO), stimulated scattering, phase conjugation, wave-guided optics, nonlinear crystals.

\section{PHY-6435 Nonlinear Guided Wave Optics}

Physics and applications of nonlinear optical interaction in fibers and planar waveguides, parameteric processes, all optical effects, solitons.

\section{PHY-6447 Quantum Optics}

Semi-classical treatment of light/matter interaction (quantized atomic states and Maxwell's equations), density matrix theory, coherent optical transition, pulse propagation.

\section{PHY-6448 Specific Laser Systems}


Review of laser principles, specifics of gas, ion, solid state, dye, metal vapor, free electron, and semiconductor lasers and power supplies.

PHZ-6204 Atomic and Molecular Spectroscopy

Atomic structures, LS and jj coupling, diatomic molecular spectra, anharmonic oscillator, polyatomic spectra, normal modes of vibration, dipole selection rule, Frank-Condon effect, spectroscopic techniques.

PHZ-6424 Optical Properties of Solids

Interband transition, free carriers, excitons, plasmas and semiconductors; k.p. theory, low dimension structures, dynamic non-linear interaction, multiphoton absorption.

MEA-5937 Laser Materials Processing

Laser beam optics; Laser-material interactions; Laser heating, melting, vaporization, plasma formation; Laser surface treatment, welding, machining; laser material synthesis, thin film deposition.

\section{RESEARCH AREAS}

CREOL faculty are engaged in a wide range of research activities in optics including: nonlinear optics, laser development, X-ray optics and devices, remote sensing and laser radar, laser/material interaction, laser material processing, solid state lasers, diffractive optics, thin film optics, opto-electronics, integrated guided-wave optics, optical switching, optical data storage, high speed optical communications, optical design and image analysis, acousto-optic devices, optical signal processing, laser propagation, infrared systems, and detector technology. This wide range of activities offer the students the opportunity to find an appropriate area of research that match their individual interests and career goals. A list of CREOL Faculty and their area of research specialization is included in Section. 7.

CREOL has over sixty laboratories fully equipped with state-of-the-art research equipment. These facilities will be shortly (Fall 1995) housed in a new 82,000 sq. ft. CREOL building designated for optical science and engineering research and education. The laboratories include: micro and solid state laser lab, laser radar lab, thin film lab, diffractive optics lab, optical switching lab, ultrafast communication device lab, nonlinear guided-wave optics lab, optical system design and image understanding lab, turbulence lab, infrared systems lab, optical signal processing lab, laser plasma lab, crystal growth lab, nanosecond, picosecond, and femtosecond laser labs, phase conjugation lab, material processing, glass processing and characterization lab, laser spectroscopy lab, scanning electron microscope facility, clean room facility, and various workstations and PC stations.

\subsection{On-going Dissertation/Thesis Research Projects}

- Development of solid state diode pumped, tunable lasers for multicolor displays, remote sensing, communications, etc.

- Development of 90 fsec tabletop laser with power $>8$ Terawatts

- Investigation of the interaction of very high optical fields with photonic materials

- Development of new photorefractive-glasses for holographic optics applications

- Development of novel polymers and polymer devices for optoelectronics

- Development of compact ultrafast, high speed, high power semiconductor lasers for photonic network applications

- Design and fabricate WDM modulators, wavelength converters, gain equalization devices, high speed demultiplexers.

- Investigate all optical devices such as demultiplexers, logic gates, interconnects, switching nodes for photonic networks.

- Development of novel applications for diffractive and hybrid holographic/refractive optical elements.

- Develop acousto-optic systems for applications in phased array antennas.

- Develop growth techniques for new NLO materials.

- Develop NLO materials characterization techniques (eg. Z-scan, EZ-scan).

- Fundamental theoretical understanding of NLO processes.

- Investigate spatial and temporal solitons and cascaded second-order NLO effects

- Development of multi-aperture coherent sensing techniques for overcoming signal fading caused by atmospheric turbulence

- Development of techniques for imaging through turbulence over a reciprocal path.

- Develop new process diagnostic, control and monitoring system development for laser processing and machining.

- Develop process modeling and optimization for laser material processing

- Development on near IR free electron laser system

- Development of new IR scene generation systems and IR detector elements

- Development of laser induced X-ray compact sources for lithography applications 


\section{CREOL FACULTY}

There are currently twenty-three tenured/tenure-earning fully supported faculty members at CREOL whose primary responsibility is the optics education and research programs. Their scholarly and academic accomplishments, and professional recognition place them among the top optical science and engineering educators and scientists in the country . Ten faculty members have been elected to the rank of fellow in their professional societies and five hold the rank of fellow in two or more societies. The faculty have extensive publication record (1,500 refereed journal papers and 1000 refereed proceeding papers) and excellent track record of providing high quality education to over $110 \mathrm{Ph} . \mathrm{D}$. students. The faculty are currently supervising $50 \mathrm{Ph} . \mathrm{D}$. and $25 \mathrm{MS}$ students. The faculty and areas of their research interest are:

Michael Bass - Professor of Physics/Electrical Engineering Solid state lasers, laser machining, laser medicine, light-matter interactions

Glenn Boreman- Associate Professor of Electrical Engineering Infrared and electro-optical systems

Bruce Chai - Professor of Physics/Mechanical Engineering/Electrical Engineering Laser host and nonlinear optical crystal growth and developments

Peter Delfyett -Associate Professor of Electrical Engineering Semiconductor lasers and optical networks

Jeff Dixon - Assistant Professor of Electrical Engineering Diode-based laser, nonlinear frequency conversion, OPO's

Luis Elias - Professor of Physics Free electron lasers

David Hagan - Associate Professor of Physics/Electrical Engineering Nonlinear optics, optical power limiting

James Harvey - Associate Professor of Electrical Engineering Optical design, scattering, image analysis

Aravinda Kar - Assistant Professor of Mechanical and Aerospace Engineering Laser-aided manufacturing and materials processing

Jin J. Kim - Professor of Physics/Electrical Engineering Semiconductor lasers, optoelectronic materials and devices, and laser spectroscopy

Patrick LiKamWa - Assistant Professor of Electrical Engineering Optoelectronics, optical switching, multiple quantum well devices

M. G. Moharam - Professor of Electrical Engineering Diffractive optics, photorefraction

Ronald Phillips - Professor of Electrical Engineering/Mathematics Optical propagation through random media

Kathleen Richardson - Assistant Professor of Chemistry Glass Science, processing, characterization and fabrication of optical materials

Martin Richardson - Professor of Physics/Electrical Engineering Laser plasmas, high intensity lasers, $\mathrm{x}$-ray microscopy, laser development

Nabeel Riza - Associate Professor of Electrical Engineering Optical information processing

William Silfvast - Professor of Physics/Electrical Engineering Lasers physics, $\mathrm{x}$-ray lithography and applications

M. J. Soileau - Professor of Electrical Engineering/Physics Laser induced damage, nonlinear optics

George Stegeman - Professor of Physics/Electrical Engineering, Cobb-Hooker Chair Nonlinear optics, integrated optics, optical switching, optical fibers 
Martin Stickley - Professor of Electrical Engineering

Laser radar, optical materials

Eric Van Stryland - Professor of Physics/Electrical Engineering

Ultra-short-pulse applications, laser damage, nonlinear optics and materials characterization

Boris Ya. Zel'dovich - Professor of Physics

Theory of light matter interaction, phase conjugation, quantum mechanics

\section{SUMMARY}

The University of Central Florida and CREOL have a very extensive education and research program in optical science and engineering. Three distinct MS and Ph.D. programs are offered: 1) Optical Science and Engineering, 2) Electrical Engineering Electro-Optics option, and 3) Optical Physics. These options provide the student with the opportunity to select the educational program that meets their individual background, interests, and career objectives. Descriptions of the degree programs, admission, articulation, degree requirements, and typical plan of study are presented. Twenty three highly qualified faculty members are currently participating in the optics programs with six new faculty to be added over the next three years. The program includes 23 specialized courses in electro-optics and lasers as well as basic electrical engineering, physics, mechanical engineering, and chemistry courses. The research component of the education program is supported by over sixty state-of-theart laboratories in a new 82,000 sq. ft. building designated for optical science and engineering research and education. 